\title{
Risk and Prevention in E-Commerce Payment
}

\author{
TaoKuang $^{1}$, Shanhong Zhu ${ }^{1,2}$ \\ ${ }^{1}$ School of Computer and Information Engineering, Xinxiang University, Henan, China \\ ${ }^{2}$ International School of Software, Wuhan University, Wuhan, China \\ 14878670@qq.com, kuangtaoxxu@163.com
}

\begin{abstract}
Network increases the development pace of people's lives, promotes the development of online shopping and the rise and prevention in third-party payment platform, this new thing is slowly infiltrated into our lives every corner. Third-party payment platform is based on trust and establish a third-party independent agencies to pay trading platform, it appears lubricating the entire e-commerce industry and plays a key role in third-party payment platform that providing a more secure, stable and efficient payment system, but the problem among it can not be ignored. Therefore, the supervision research about third-party online payment platform has important practical significance for the prevention of payment and settlement risk.
\end{abstract}

Index Terms - e-commerce, third-party payment platform, supervision, prevention

\section{Introduction}

Network led to the development pace of people's lives, promote the development of online shopping and the rise of third-party payment platform, this new thing is slowly infiltrated into our lives every corner. Third-party payment platform is based on trust and establish a third-party independent agencies to pay trading platform, it appears lubricating the entire e-commerce industry. Third-party payment platform is a non-financial institution which establishes a connection between merchants and banks as credit guarantees and technical support services while reduces transaction costs and facilitates public payment. Third-party payment platform generated by the rapid development of online shopping transactions and plays a key role not only to the success of each transaction, but also a lot of money related to a range of security and social stability. According to an incomplete statistics, China's third-party payment platform transaction amount has reached 274.3 billion yuan, more than 976 billion yuan in $2007181 \%$ in 2008[1].

\section{Overview of Third-Party Payment Platform}

With the progress of the Internet and development of network technology, people living increasingly close ties with the network, online shopping has become common practice, in which buyers can not see the arrival, the seller can not see the money transactions, to ensure transactions smoothly, it must require a high reputation, both consumers and sales as a trusted third party intermediary to help complete the transaction[2]. The Intermediaries talked about here is what we are discussing third-party payment platform.

Third-party payment platform is an independent agency with a certain strength and reputable to protect the transaction payment. In the transaction, the buyer bought the commodity and pay the purchase through a third party payment platform which should inform the seller shipped the goods immediately after the receipt of payment. When the buyer receives the goods satisfied, he will notify the third-party payment platform pay to the seller. Third-party payment platform covers a variety of bank card interface integrated into a complete settlement with the bank's defray[3].

The proposed concept of third-party payment platform in Davos, Switzerland in 2005, Mayun proposed the concept of third-party payment platform, he believes the key to all problems is the e-commerce security that e-commerce out of the question without security trading environment. Domestic common third-party payment platform like YeePay EPRO (Beijing Information Technology Co., Ltd), AliPay, TenPay have very strong momentum from the speed of development. Sadie consultant's analysis shows that in recent years, third-party payment platform to pay as much as the amount has reached tens of billions, representing the proportion of online payment about $36 \%$ [4]. As of 2010, the third-party payment platform has entered a rapid development period[5].

\section{The risk of Third-Party Payment Platform}

Third-party payment platform is relying on the Internet, the network data transmission and storage of electronic and traditional banking business, as there are many technical problems and compliance issues, the third-party network payment there are many risks to run in reality.

\section{A. The risk of the reception fund in third-party payment platform}

Third-party payment platform service providers generally have the ability to sequestrate the funds and make it a part of the same functionality with banks. The funds in the account of the service provider will be a period of retention with the e-commerce transactions in the payment process and the number of funds will also precipitate rapid expansion, according to reports, in the virtual account funds remain almost every day up to several millions of dollars, a large number of customer funds precipitation may lead to riskier investments or other activities, coupled with the differences in levels of business operations management, may lead to liquidity risk, credit risk and transaction platform for enterprise operational risk[6].

Third-party online payment platform directly control transaction amount which may be called ultra vires trading 
financial risk[7]. And because the anonymity and hidden of online transactions, the third party payment transactions may be achieved by making a false fraudulent means. The most harmful of the financial risk is fund ${ }^{[8]}$. Based on the current trading rules, the amount paid in the third-party online payment platform usually be precipitated with 3-7 days, so at any time payment platform in the tens of millions of dollars precipitation. With future growth in the number of users, the capital amount of precipitation will be very great.

\section{B. The financial risk of the third-party payment platform}

Because the characteristics of electronic payment, both sides in transactions are not met each other[9] The third-party payment platform trading is anonymity and with the incompleteness of the information online, it is difficult to identify the true source and destination of funds, so that some use of third-party platform illegal transfer of funds, money laundering, withdrawal of creditcard, bribery, fraud, gambling and tax evasion and other activities became possible.

For example, the withdrawal of creditcard. Some e-commerce transactions by using the domestic several large e-commerce sites on their own "buy sell" false tradings. Parties to the transaction is in a virtual card account or two discuss sides, credit card holders in e-commerce site by relatives or friends set up fake identity card shop, and then use their creditcard in the shop buy virtual goods, making substantial use of credit cards to Withdrawal Of CreditCard[10].

\section{The ethical risk of the third-party payment platform}

E-commerce transactions choose to pay from third-party payment platform because the strength of its third-party payment platform, brand, reputation recognition. Third-party payment platform make up credit intermediary roles which not only offset the lack of a social credit system, but also increases the risk of the transaction and payment risk, especially when the development of electronic payment transactions to a certain size. If the third-party payment platform has losses within the management reasons, the whole payment and settlement systems will certainly be a considerable impact that will threaten the entire payment system security and stability.

\section{The network security risk of the third-party payment platform}

There is a network security risk. This is mainly reflected in three aspects: First, the data transfer process attack will threaten user's fund security; the second is inherent in online payment. Application security design flaws could be exploited and endanger the security of the entire system; the third is likely to break through the network against computer viruses, invasion of the host of online payment system, resulting in data loss and other serious consequences[11]. Research data shows that online banking and online payment security risks of exposure to the most profound impression on users, recognition rate of $36 \%$, higher than the evening's other content.

Online banking and online payment security is the basis of their service users. Once the user bank account number, ID number, password and other information be leaked in the transaction, will give users direct property damage. With online banking and online payment penetration rate of Internet users increased steadily, account and password security has become the focus of Internet users[12].The network security, disaster prevention, anti-virus problem are the most concerns when consumers use third-party payment platform. The third major cause of security problems to pay is in the following: the first one is hackers steal card information and password from the user's computer which is the main exposure; the second is transaction information which transmitted over the Internet intercepted by hackers, the possibility of this happening is minimal; the third is the user being diverted to phishing to deceive card number and password, this situation is the main user deceived.

\section{Strengthen the Security Protect of Network Payment}

First, We must strengthen the security protect of network payment and accelerate the development of security technology that combined both together to prevent online banking system vulnerabilities and hacker attacks at the same time ensure a good environment for online transactions. We should post the recent fake phishing sites on the payment pages which would make consumers to increase vigilance and reduce payment risks.

Second, We would defined the consumer financial security measures if meet event of force majeure and how to compensate the loss caused by the delay or failure of the banking system failure like as viruses, Trojan horses and hackers attacks. Network security technology is the most important side in the third-party payment platform and we must increase the human and material resources to build solid network protection fortress. If the problem can not be resolved, other issues that can only be on paper, it is difficult to achieve.

\section{References}

[1] Central bank for the first time "fishing expedition" third party payment regularization and speed [EB/OL] [2009-4-21], http://finance.sina.com.cn/roll/20090421/04076127196.shtml.

[2] WANG Xu-ping; CHEN Ao, Evaluation and Optimization of Vendors based on E-business, Policy-making Reference, 2004(08):49-53.

[3] Wang Ya-ling. Guo Hong-yu, Research on Regulation of Third-party Payment Platform in Functional Perspective, Journal of Beijing Technology and Business University(Social Science), 2011(10).

[4] Yang juan, Third-party electronic payment in the study of consumer protection, Southwest Finance, 2010(10).

[5] Zen jixia, The Research on Risk Monitoring for China's Electronic Payment, Hunan University, 2009.

[6] Zhu jing, E-commerce legal issues related to research third-party payment, China University of Political Science, 2011.

[7] Huang jingyi, On the payment of third-party legal and regulatory institutions, On the issue of the South, 2010(04).

[8] Tang tiantian, Third-party payment platform and its regulation of, China Business \& Trade, 2011(24):245-252. 
[9] Zhu jixin. Zhang li. Zhang liangliang, Third-party payment regulation of international experience and inspiration, China financial, 2010(12).

[10] Chou jin, Third-party payment platform to strengthen regulatory proposals, Journal of Financial Development Research, 2009(5).

[11] Zhang defu, Third-party online payment service regulatory model of international comparison and reference, Financial Accounting, 2008(6):9-13.

[12] Hou chunjun, the main problems and regulatory strategy of China's third-party payment platform, E-Business Journal, 2009(7):44-46.

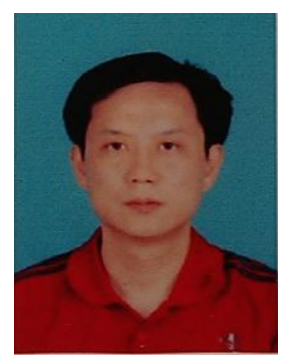

Tao Kuang, was born in China in 1975. He earned a master's degree in software engineering in the School of Information Engineering at Zhengzhou University. $\mathrm{He}$ is employed as a Associate Professor in Xinxiang College, where he is now a director of the Department of Network and Information Security Department. His research interests include computer multimedia, virtual reality application, embedded system and application, data mining, computer communication and so on. 